\title{
Materials and the Global Environment: Waste Mining in the 21st Century
}

\section{Robert U. Ayres, John Holmberg, and Björn Andersson}

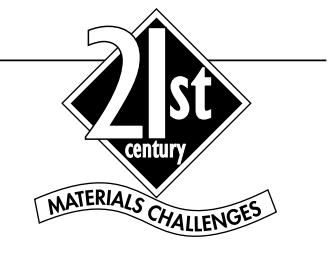

What's a mountain got that a slag pile hasn't?

-Jean Giraudoux (1882-1944)

The Madwoman of Chaillot, Act 1

The environment makes up a huge, enormously complex living machine that forms a thin dynamic layer on the earth's surface, and every human activity depends on the integrity and the proper functioning of this machine.

-Barry Commoner The Closing Circle, 1971

\section{Background}

Sustainability is supposed to be the watchword of the coming century. Kenneth Boulding ${ }^{1}$ characterized the economic system of the 19th century as a "cowboy economy," meaning that resources were essentially not a limiting factor. In contrast, he noted that in the future we must prepare to live in a "spaceship economy," adopting Barbara Ward's famous metaphor of "Spaceship Earth." In a spaceship, all materials must be recycled (or discarded into space). On the earth, the goal of total recycling or "zero emissions" is obviously a very distant one. Even the biosphere has not achieved it. Yet, for some materials, especially certain metals, this goal must be taken seriously, even in the fairly near term.

The relationship between materials and the environment in the coming century can be considered from two very different perspectives. The economic perspective sees materials as consumables and-to some extent-as wastes and pollutants, but always as abstractions, lacking in differential physical attributes. Resource economics concerns itself with availability and/or scarcity and the implications for economic growth. Mainstream economics considers materials hardly at all, being concerned with capital, labor, and "technical progress," the latter being measurable only in terms of increasing factor (especially labor) productivity, of exogenous origin. In mainstream economics, scarcity hardly exists (in free competitive markets) except as an abstract cause of price increases and a possible inducement to innovation. Environmental economics considers materials essentially only as wastes and pollutants, and concerns itself mainly with strategies for abatement and costs thereof.

The perspective of engineering, materials science, and environmental science is very different, of course. In this perspective, transformation processes and attributes are of fundamental importance. In this article, we adopt the latter perspective, for the most part, while attempting to remain in touch with the former. The point of contact between the two perspectives is the conditions for development and adoption. Economists ask whether a technology is likely to be economically competitive in a free-market context. Engineers tend to look first for technical feasibility, then at cost. Engineering cost analyses are often criticized by economists as being too optimistic in disregarding the "hidden costs" of innovation. Economic analyses are often criticized by engineers and scientists as failing to recognize the potential for future cost reduction as a new technology is adopted. Doubtless the argument will continue.

We focus here on the materials perspective as applied to long-term sustainability. There have been many definitions of sustainability, but we need not adopt any one of them. On the contrary, it is sufficient for our purposes to note that the extraction and dissipative uses of most materials, especially rare and toxic metals, are clearly unsustainable. There are two reasons. The first is that known reserves and probable undiscovered resources of a number of important metals are severely limited. (We do not argue that reserves will be exhausted in the next few decades, but neither can it be assumed that future supplies are unlimited.) The second reason for unsustainability is more urgent: It is that the assimilative capacity of the earth's environment is limited. In some regions, the state of the local environment is already severely damaged.

In the case of rare and toxic metals, environmental damage occurs not only as a consequence of dissipative usagethe buildup of cadmium in topsoil is an example-but also as a consequence of mining and smelting operations. The

Materials Challenges For The Next Century presents a series of articles speculating on the role of materials in society in the coming century and beyond. seriously degraded landscapes around the copper-nickel smelters in Sudbury, Ontario, or the copper smelter at Butte, Montana, illustrate the latter problem. While not posing any major toxicity problems, the use of major abundant elements such as aluminum and iron may also seriously affect the environment by the sheer size of mining, smelting, and refining operations.

However, the buildup of a more sustainable industrial society comprising a larger share of a growing world population will also require an increased use of a range of metals. As an example, one of the major technological challenges of the century will be the transformation of the energy system to reduce its environmental impacts, most notably climatic change due to global warming. Limiting humancaused climatic change will require a rapid diffusion of a range of new technologies that can transform and use energy more efficiently and of technologies that can supply energy without increasing the concentration of carbon dioxide in the atmosphere. Many technologies with the potential to contribute to such a transformation, such as solar photovoltaics, lowemissivity and electrochromic windows, batteries, and fuel cells, are based on advanced materials of which many make use of rare and toxic metals. As another example, an increased use of a lightweight metal such as aluminum could decrease the energy intensity of transportation.

The bottom line of this reasoning is that we may need to seek a range of new opportunities to minimize society's materials losses. One such opportunity is waste mining. The more our economy recycles and recovers useful metals (and other materials) from its wastes, the less mining will be needed and the less environmental damage will result from waste disposal. We now consider three specific opportunities.

\section{Coal Ash}

Coal is burned in enormous quantities: approximately 3.3 billion tons in 1998, supplying a quarter of the global energy demand. The main waste from coal combustion is carbon dioxide, making it a great contributor to global warming. This fact does not necessarily disqualify coal from taking part in a more sustainable energy system. Gasification of coal followed by a water shift reaction results in two pure gases: carbon dioxide and 
hydrogen. ${ }^{3}$ The carbon dioxide can be pumped underground and stored in old gas and oil fields or aquifers while the hydrogen is combusted to produce electricity or used as fuel in fuel cells rendering water as the only emission.

While this technology could sequester the carbon dioxide, a large amount of waste would still result from coal combustion. At least $10 \%$ of mined coals is ash. The ash content of coals varies widely, but the averages for Australia are 9-14\%; for China, 13-14\%; for Russia, $10-15 \%$; and ranging up to $40 \%$ for some Indian and North Korean coals. In the United States (1985), about $74 \%$ of the ash was released in the form of fly ash, the remainder being bottom ash or clinker $(20 \%)$ and boiler slag $(6 \%)$.

In North America, Western Europe, and Japan, electrostatic precipitators (ESPs) remove most of the ash from the smoke (up to $99 \%$ ); even so, the quantities are so large that fly ash is a significant source of environmental accumulation of several of the heavy metals, including arsenic, cadmium, copper, nickel, mercury, vanadium, and zinc. Unfortunately, ESPs are much less efficient-if they are installed at all-in other coal-burning countries such as Russia, China, and India. Where ESPs are in use, of course, the ash is collected and disposed of, mostly in landfills.

Some ash is utilized productively. A detailed study in the United States for 1986 revealed that usage rates were $18 \%$ for fly ash, $27 \%$ for bottom ash, and 52\% for boiler slag. Uses were (1) as a cement additive; (2) as aggregate for concrete; (3) for fill, road ballast, and ice control on roads; (4) as a soil conditioner (for acidic soils); and (5) as a constituent of drilling muds. These applications only make use of the very crude properties of the ash.

Coal ashes vary considerably in composition, but a typical dry ash would contain $40-45 \%$ silica, $16-20 \%$ alumina, $18-22 \%$ iron oxide (hematite), $5 \%$ calcium oxide (lime), and $2 \%$ sulfur trioxide (adsorbed). The remainder, $3-4 \%$ by weight, consists of a range of metal oxides. There are significant metal values in the ash. A rough estimate indicates that the metal content of coal ash is far larger than the current refinery production for many metals.

The aluminum content of the annual production of coal ash exceeds the aluminum recovery from bauxite by about $50 \%$. Of the minor elements, germanium and gallium are extremes for which the contents in coal exceed the primary refinery production by a factor of more than 200 . Other examples are lithium, vanadium, and selenium, which have coal-content-torefinery-production ratios of 3:4. These figures are based on typical concentrations in coals. Since the concentrations vary a lot between different coals, specific coal deposits may contribute substantially to the flows of particular elements. As an example, Tateda et al. ${ }^{4}$ report an indium content of Japanese coal ash that exceeds world refinery production by a factor of 10 .

The more our economy
recycles and recovers useful
metals (and other materials)
from its wastes, the less
mining will be needed and
the less environmental
damage will result from
waste disposal.

Beneficiation of ash can be accomplished in stages. The first step would probably be magnetic separation to obtain an iron-rich fraction and an iron-poor fraction. The feasibility of magnetic separation has been demonstrated. ${ }^{5,6}$ It yields a material with a hematite fraction of between $60 \%$ and $70 \%$, which is entirely suitable for pelletizing and use in the integrated steel sector. Another possibility is to smelt the ash in an electric arc furnace, even without magnetic separation. ${ }^{7}$ In one experiment, the process yielded ferrosilicon with an iron content of $61 \%$, a silicon content of $33 \%$, and carbon content of $2 \%$, with the remainder enriched in chromium ( $2 \%$ ) and vanadium ( $1 \%)$. Other trace elements accounted for only $1.16 \%$ of the mass of the ferrosilicon fraction. All of the alumina and silica, plus some iron, sulfur, and most of the other trace elements, ended up in the furnace slag.

The alumina content of the slag in the example just described amounted to $35 \%$, which is only marginally lower than the fraction in some bauxites. As a matter of fact, the U.S. Bureau of Mines (USBM) carried out a major research effort in the early 1970s (responding to the threat of a possible alumina producers' cartel) evaluating 18 possible processes for alumina production, starting from either clay or anorthosite, at then-current (1973) U.S. prices. None was competitive with the Bayer process. ${ }^{8}$ However, fly ash was not considered as a raw material in that study. Since the first two (energy-intensive) steps in any process starting from clay or anorthosite are grinding and dehydration, it is noteworthy that the use of fly ash as a feedstock would eliminate both steps and the costs associated with them. ${ }^{9}$

Later, the Electric Power Research Institute (EPRI) reconsidered the processes evaluated by USBM, mainly from the perspective of reducing dangers from heavy metals leaching in landfills. Two processes were studied in detail, the direct acid leach (DAL) process and the pressure digestion acid leach (PDAL) process. The first was considered a "minimum treatment" process for removing those heavy metals most likely to leach out of ash in a landfill. The second was considered a "maximum treatment" process for recovering all of the metals in the ash.

The DAL process utilizes either hydrochloric or sulfuric acid, depending on availability. At a slightly elevated temperature, stoichiometric quantities of acid react with the fly ash, removing (under optimal conditions) about $45 \%$ of the aluminum, $75 \%$ of the iron, $64 \%$ of manganese, and $29 \%$ of the titanium in the ash. These are the soluble fractions. The remainder of the ash residue is insoluble at ambient temperatures and therefore innocuous in a landfill. The next step is an anion exchange medium, where all the metals except aluminum remain in the medium. The aluminum remains in solution (as chloride or sulfate), from which it can be recovered by fractional crystallization. The last step in the hydrochloric acid version of the DAL process is reaction with lime to precipitate aluminum oxide (alumina), leaving calcium chloride in solution. If sulfuric acid is used for leaching, the final reaction requires caustic soda to achieve separation. In the chloride case, the EPRI study suggested that for a hypothetical plant operating on an industrial scale of 1 million metric tons (MMT) per year, the DAL process would be profitable on its own, with a return on capital of $40 \%$ and a payback time of 2.8 years. ${ }^{10}$ That it was not adopted at the time (or since) can probably be attributed to perceptions of risk-which accompany any new industrial process-rather than any flaw in the analysis.

It is of some interest to note that an aluminum smelting process starting from aluminum chloride rather than alumina (the so-called ALCOA process) that was never implemented beyond pilot stage might be even more profitable, since the economics of the ALCOA process have been calculated on the basis of chlorinating alumina to produce aluminum chloride, whereas the economics of the DAL process assumed the reverse case, converting aluminum chloride into alumina. ${ }^{11}$ However, the advantages of the combination of the two processes cannot be taken 
altogether for granted, inasmuch as the aluminum chloride from the DAL process would be wet (and aluminum chloride is hygroscopic), thus requiring an energyintensive intervening dehydration step.

The PDAL version of the leaching process would recover still more of the metals, including the trace metals, but at a higher capital cost. Nevertheless, the economics apparently depend largely on the extent to which caustic soda and chlorine can be recycled within the process.

The recovery of toxic metals such as cadmium, mercury, and lead could be warranted to reduce the toxicity of the ash. Additional incentives to metal recovery could be an increased demand for minor metals such as gallium, germanium, selenium, and indium for their use in materials such as gallium arsenide, copper indium gallium selenide, indium tin oxide, and silicon germanium alloys for various electronic applications, including solar photovoltaics and energy-efficient windows. ${ }^{12}$ Also, an increased demand for lithium, vanadium, and cobalt for various battery applications, including electric vehicles, can be expected. ${ }^{13}$

\section{Phospho-Gypsum}

Phosphorus is one of the nutrient elements essential to life. Unlike carbon, nitrogen, and sulfur, it is not recycled biologically from sea to land, except to a very minor degree (mainly by bird droppings, or guano). Phosphate fertilizer is derived from a sedimentary rock known as apatite. The two major components of apatite (by dry weight) are phosphorus pentoxide and calcium oxide, with a variable amount of silica (ranging from $2 \%$ to $17 \%$, but typically around $6 \%-8 \%$ ) plus a small but significant fluorine content, usually between $3 \%$ and $4 \%$. Other oxides account for the remainder. Trace elements of importance include uranium and thorium.

Phosphate rock is treated with concentrated sulfuric acid to yield phosphoric acid, from which all other phosphate fertilizers are derived. This process consumes half of the sulfuric acid used in the United States, and generates on average about three tons of calcium sulfate (phosphogypsum, PG) per ton of phosphoric acid.

In principle, $P G$ is interchangeable with gypsum from natural sources and could be used for the same purposes. The environmental benefits are obvious: Enough byproduct PG is produced by the phosphate industry to eliminate any need for gypsum mining. In practice, however, PG is classed as a hazardous waste in the United States (due to its trace metal content, including thorium, uranium, and cadmium), and its disposal is a problem for the industry. To overcome this problem, means of purifying PG by removing trace metals would have to be developed.

In addition, means of dehydrating the (wet) PG waste would need to be developed. The key to success in this case would seem to be to integrate PG production with one or more large-scale exothermic processes, such as sulfuric acid production.

In the United States, some of the fluorine is recovered as fluosilicic acid, and utilized $(75 \%)$ for municipal-water fluoridation and $(25 \%)$ by the aluminum industry for the production of aluminum fluoride, used in the Hall-Heroult electrolytic smelting process. ${ }^{11}$ This product is made by reacting the fluosilicic acid with aluminum hydroxide. At least two alternative processes are available for converting the fluosilicic acid to salable calcium fluoride (equivalent to acidgrade fluorite). One is a reaction with ammonia to generate ammonium fluoride (soluble) and silica (insoluble), followed by a reaction with calcium hydroxide (from lime and water), regenerating the ammonia and yielding calcium fluoride (insoluble). The other is a reaction between fluosilicic acid and phosphate rock, which yields marketable phosphoric acid and calcium silicon hexafluoride, which is hydrolyzed to yield silica and acid-grade calcium fluoride. An even more interesting process under development involves neutralizing fluosilicic acid with caustic soda, yielding sodium fluorosilicate, which is then reacted with sodium metal to produce pure silicon metal and sodium fluoride. The Stanford Research Institute has claimed that this process could produce electronic-grade silicon more cheaply than the current Siemens (chlorination) process. Another benefit of utilizing fluosilicic acid is that it could potentially eliminate the need to mine natural fluorite.

\section{Red Mud}

Red mud is the waste generated by alumina production from bauxite. Producing one ton of metallic aluminum requires two tons of alumina, which in turn takes about four tons of ore (bauxite), due to the presence of iron oxides and other impurities. This means that about two tons of red mud is generated per ton of metallic aluminum. World production of red mud is roughly 30 million tons per year (dry basis).

The red mud consists of alumina, iron oxide, titanium oxide, and small quantities of silica, calcium oxide, and alkali. It also contains trace elements such as $\mathrm{P}, \mathrm{V}$, $\mathrm{Mn}, \mathrm{Cr}, \mathrm{Mg}$, $\mathrm{Zn}$, and $\mathrm{Ga}$.
The red mud poses a major disposal problem. It has several properties that make disposal difficult, including high alkalinity ( $\mathrm{pH}$ of the order of 11 or higher), high water content (about $60 \%$ ), and physical characteristics similar to wet clay. Red mud is disposed in different ways, including ocean dumping, but the mainstream goes to large surface impoundments. In arid climates, dry stacking, a method that uses solar radiation to concentrate the mud, is held to be the best method now available. The dry stacking method requires large drying areas, which raises the possibility of dust generation. Revegetation has also been suggested, despite the limiting factors (e.g., high $\mathrm{pH}$, high salinity, low porosity, and complete absence of nutrients or organic constituents). ${ }^{14}$

One task of materials science
will be to explore ways not
only to design materials that
make products work
increasingly better, but also
to choose compositions that
facilitate a closing of the
material flows on
"Spaceship Earth."

Efforts have been made to use the red mud beneficially, but to date few economically viable solutions have been found. However, the cost of disposal will most certainly increase; then, different options will be of more interest. First, there are options to use the red mud with very little treatment (e.g., for levee construction material, road embankments, landfill cover, synthetic soils, fertilizer fillers, and remediation of coastal erosion). ${ }^{15}$ Second, there are options to use the red mud with moderate treatment. For instance, bricks can be produced by adding sodium silica to the mud particles, then a reaction between the alumina silica and sodium ions takes place, cementing the particles together. The bricks need only be dried in the sun, instead of being fired in ovens. ${ }^{16}$ Other building products, such as doors, lumber, and utility poles, can be produced from dried red mud ( $<0.5 \%$ water). ${ }^{17}$ It has also been found that up to $37 \mathrm{wt} \%$ of red mud can be added in the production of ceramic glazes. ${ }^{18}$

Third, there are future options to extract metals from the red mud: It has been shown that over $90 \mathrm{wt} \%$ alumina 
can be recovered from red mud by sodaash sintering and caustic leaching. Hematite can be carbothermically reduced with degree of metallization of over $94 \mathrm{wt} \%$. If smelted, the concentration of titanium oxide in the slag will be high enough to justify its recovery by an acid-leach process. ${ }^{19}$ Extraction of scarcer elements from red mud, such as zirconium, has also been suggested. ${ }^{20}$

It is still too early to tell which uses of red mud could become economically viable. It is clear that the disposal cost will be of central importance for all solutions and that local conditions will be important for all the options involving minimal treatment.

Here we have explored some opportunities to recover materials from waste streams. It is becoming more and more evident that the acceptance and cost of these materials will be dependent on such opportunities as the limits of waste deposition, nature's capacity to assimilate toxic elements, the acceptance of land transformations of mining operations, and the availability of scarce metals. In this development, one task of materials science will be to explore ways not only to design materials that make products work increasingly better, but also to choose compositions that facilitate a closing of the material flows on "Spaceship Earth."

\section{References}

1. K.E. Boulding, "The Economics of the Coming Spaceship Earth," in Environmental Quality in a Growing Economy, edited by $\mathrm{H}$. Jarett (Johns Hopkins University Press for Resources for the Future, Baltimore, 1966).

2. B. Ward, Spaceship Earth (Columbia University Press, New York, 1966).

3. R. Williams, "Advanced Energy Technologies," in World Energy Assessment, edited by J. Goldemberg (United Nations, New York, 2000). 4. M. Tateda, M. Ike, and M. Fujita, Resources, Conservation and Recycling 19 (1997) p. 93.

5. Z. Nowak, "Recovery of Minerals and Elements from Ash," in Coal Ash Utilization: Fly Ash, Bottom Ash and Slag, edited by S. Torrey (Noyes Data Corp., Park Ridge, NJ, 1978).
6. M. Roy, J. Murtha, and G. Burnet, Industrial Applications of Magnetic Separation (IEEE Press, Piscataway, NJ, 1979).

7. W.E. Morton, in Coal Ash Utilization: Fly Ash, Bottom Ash and Slag, edited by S. Torrey (Noyes Data Corp., Park Ridge, NJ, 1978).

8. F.R. Peters and P.W. Johnson, Revised and Updated Cost Estimates for Producing Alumina from Domestic Raw Materials, Information Circular (8648), (U.S. Department of the Interior, Washington DC, 1974)

9. C.K. Yun, S.B. Park, and W.H. Park, "Aluminum Kombinat: An Integral Utilization of Low Grade Anthracites for Simultaneous Recovery of Aluminum and Energy," presented at the 4th Joint Meet., MMIJ-AIME, Tokyo, 1980.

10. R.M. Canon, T.M. Gilliam, and J.S. Watson, Evaluating Potential Processes for Recovery of Metals from Coal Ash (CS-1992) (Electric Power Research Institute, November 1981).

11. R.U. Ayres and L.W. Ayres, Industrial Ecology-Towards Closing the Materials Cycle (Edward Elgar, Cheltenham, UK, 1996) pp. 43-44, 120

12. B.A. Andersson, Progress in Photovoltaics 8 (2000) p. 61.

13. B.A. Andersson and I. Råde, "Metal Resource Constraints for Large-Scale Battery Electric Vehicle Fleets," Transportation Research Part D-Energy and the Environment, in press.

14. R.P. Harrison, "Altered Landscapes: 'Red Mud' and the Aluminum Industry," presented at the Second Intl. Symp. on Iron Control in Metallurgy, Ottawa, Canada, October 20-23, 1996.

15. S.O. Brown and D.B. Kirkpatrick, "Red Mud Product Development," in Light Metals 1999 (Mineral, Metals and Materials Society, Warrendale, 1999) p. 25.

16. P. Newton, Making Bricks with Red Mud in Jamaica, International Development Research Center Report Vol. 21, No. 2., Ottawa, Canada, 1993. 17. W. Brown, Century-Board (personal communication, 2000).

18. N. Yalcin and V. Selvinc, Ceramics International 26 (5) (2000) p. 485.

19. B. Mishra, D. Kirkpatrick, and M. Slavik, in Proc. EPD Congress 2000 (Mineral, Metals and Materials Society, Warrendale, 2000) p. 369.

20. T. Kasai and T. Mizota, J. Mining Mater. Proc. Inst. Jpn. 112 (3) (1996) p. 131.

Robert U. Ayres was Sandoz Professor of Environment and Management (now emeritus) and Director of the Center for the
Management of Environmental Resources (CMER) at INSEAD in Fontainebleau, France. From 1979 through 1992, he was a professor of engineering and public policy at Carnegie Mellon University. He has written or co-authored 16 books and edited or co-edited 10 others as well as numerous journal articles and book chapters. His work in recent years has focused on industrial metabolism and industrial ecology.

John Holmberg is associate professor and head of the Department of Physical Resource Theory, Chalmers University of Technology and Göteborg University in Sweden, where he received his PhD degree. He is the scientif$i c$ director and a board member at the Natural Step Foundation, an international organization focused on the socially and ecologically sustainable society. He is also a member of the scientific council to the Swedish Environmental Innovation Center, Gothenburg Academy for Management of the Environment, and the Sankt Jorgen Environmental Park, Göteborg, Sweden. His main research interests are within the emerging field of industrial ecology. He has developed widespread principles and indicators of sustainability and is currently coordinating a project concerning safeguarding quality in the European turnover of aluminum.

Björn Andersson is a researcher in the Department of Physical Resource Theory at Chalmers University of Technology and Göteborg University in Sweden. In several papers and in his PhD thesis "Materials Constraints on Technology Evolution," he explored constraints related to metal scarcity and environmental effects, and the introduction and large-scale diffusion of emerging energy technologies such as photovoltaics, batteries, and fuel cells. He is involved in interdisciplinary studies of technical change and sustainable development involving elements of technology assessment, energy modeling, industrial ecology, and the economics of innovation.

\section{"Habitat: Sensors may be used to measure wind speeds or earthquake-generated
pressures and provide for a temporary increase in strength at anchorage points
of the roof and other vulnerable locations."}

"We look forward to the tube of biomedical 'glue' which we simply squeeze on to a cut to seal and heal it."
"A single disk with a petabit of storage would provide approximately a movie a day for over 60 years." 